\title{
The Migration Mechanism of Arsenic lons Under the Effect of Temperature in Yunnan Laterite
}

\author{
Peng Liu ${ }^{1}$, Ying Huang ${ }^{2}$, Min $\mathrm{He}^{1, \text { * }}$ \\ ${ }^{1}$ Department of Architectural and Civil Engineering, The Oxbridge College Kunming University of science and technology, Kun Ming, \\ China \\ ${ }^{2}$ The Power Engineering Academy, Kunming University of Science and Technology, Kun Ming, China
}

Email address:

liupeng611@163.com (Peng Liu), hemin0426@163.com (Min He), huangying3764@sina.com.cn (Ying Huang)

\section{To cite this article:}

Peng Liu, Ying Huang, Min He. The Migration Mechanism of Arsenic Ions Under the Effect of Temperature in Yunnan Laterite. Earth Sciences. Vol. 4, No. 4, 2015, pp. 146-149. doi: 10.11648/j.earth.20150404.12

\begin{abstract}
This article considers the temperature influence of pollution transportation base on the transportation model of pollution in groundwater to finish the article by using Macro and micro method, the combination of theoretical analysis, experimental research methods and numerical simulation. Established the transportation model for consider temperature and solved by soft of Femlab. The result shows that the more close to the pollution source, the concentration is larger, the farther away from the source of pollution; the concentration value is small, which is consistent with the trend of pollution in the general case. With the increase of temperature, the concentration of pollution increased, among them, the higher the temperature, the rising trend is more obvious, that the migration and diffusion of pollution in the role of temperature. The temperature could increase depth of pollution diffusion. The results will also provide theoretical guide and technological support for the sustainable development of Yunnan economy and ecology as well as for the future laboratory experiments.
\end{abstract}

Keywords: Groundwater, Arsenic Pollution, Migration Model, Laterite, Migration Mechanism

\section{Introduction}

The came from departmental pollution more and more, and the pollution level went over severity of the both with urbanize tenor and industrial economy. The pollution crescent include the heat engine plant generate electricity bring solid waste (such as coal mine spoil and coal fly ash), the plant, paper mill and smelter reveal raw material plant in process of production (such as petroleum and heavy metal substance), the fertilizer and pesticide in agriculture and the consumption residues and offal among life and so on. Expulsion the virulence and deleterious pollution will be influence the surrounding environment. The familiar differential element with: $\mathrm{N}, \mathrm{F}, \mathrm{Cl}$, $\mathrm{P}, \mathrm{Ca}, \mathrm{Hg}, \mathrm{As}, \mathrm{Pb}, \mathrm{Cu}, \mathrm{Cr}, \mathrm{Fe}, \mathrm{U}, \mathrm{Se}, \mathrm{Cd}, \mathrm{Co}, \mathrm{Mn}$ and so on ${ }^{[1]}$. The differential elements have got definite perniciousness, rough the rainfall eluviations influent underground and pollute groundwater.

Arsenic is one of the most widespread and dangerous toxic substances in the environment, and the contamination of drinking water is especially problematic in developing countries (Mandal and Suzuki, 2002; Naidu et al., 2006; Smedley and Kinniburgh, 2002). Arsenic pollution of groundwaters can occur through natural and anthropogenic processes. In China, for instance, the geogenic release of arsenic from sedimented iron phases under reducing conditions is seen as the main cause for groundwater contamination. Co-deposition of organic matter with arsenic enriched iron phases in these sediments probably favours this subsequent reductive arsenic mobilization.

The pollution stacked on the soil to do in favor of influence towards stack regional soil and groundwater. Take a wide view near few decades, the study procure some important production about the chemical weathering of the camp tailings, the heavy metal elementary exoneration and enrichment, the biotic environment geochemistry effect and the toxic element to camp environment relation in soil. The study established theoretical basis for more examined in depth for later generations ${ }^{[2-4]}$. Yet seldom scholar considers the influence of pollution transportation towards temperature. Therefore, this article base on the transportation model of pollution and consider the influence of pollution transportation towards temperature. 


\section{Establishment the Transportation Model}

\subsection{The Soil Water Movement Model Under the Influence of Temperature}

The change of soil temperature has a direct impact on retention and movement in soil moisture, temperature of soil in many physical processes play a role, soil water and heat transport is very complex and important research problem. The movement of water and heat in the soil affects the soil moisture movement, and the soil water movement affects the soil heat capacity and the heat conductivity, so that the soil temperature can affect the soil temperature. Green-Ampt infiltration formula is simple, and has a certain physical model basis, has long been widespread attention, since the 1970s, the Green-Ampt infiltration equation was applied good effect to heterogeneous soil, initial moisture content of non-uniform distribution of soil, layered soil, muddy water, the intermittent infiltration. Therefore, the temperature influence of soil moisture movement model can be expressed as:

$$
\left\{\begin{array}{l}
I=\left(\theta_{s}-\theta_{0}\right) Z_{f} \\
q=K_{t}\left(1+\frac{H_{m}}{Z_{f}(t)}\right)
\end{array}\right.
$$

Where I is the cumulative infiltration $(\mathrm{cm}) ; \theta \mathrm{s}, \theta_{0}$ is the soil saturated and initial moisture content (\%); $\mathrm{Hm}$ is generalization of the wetting front suction $(\mathrm{cm}) ; \mathrm{Z}_{\mathrm{f}}$ is a generalization of the wetting front position $(\mathrm{cm})$; $\mathrm{q}$ is surface infiltration flux $(\mathrm{cm} / \mathrm{min}), \mathrm{Kt}$ is almost saturated zone of the saturated hydraulic conductivity $(\mathrm{cm} / \mathrm{min})$, even under water logged conditions, soil generalizability area also have part of the pore is not filled with water. Therefore, $\mathrm{Kt}$ is less than soil saturated water ratio $\mathrm{K}$; $\mathrm{t}$ is the infiltration time. Obviously, the effect of temperature on $\mathrm{Z}_{\mathrm{f}}$ is passed through temperature, such as water rate, suction and saturation.

\subsection{Transportation Equation of Water Temperature}

Substantially, the water temperature is some heat energy reaction in water substance. The transportation equation of water temperature in groundwater could be established according to heat balance and transportation diffuse field of micro-modular. The sum of the number of variations for caloricity of passes in and out micro-modular, the procreant caloricity of convection, the caloricity of the principle congruence equal the caloricity of total variation in micro-modular. Condition instance, the micro-modular is an infinitesimal modular and situated in groundwater, the temperature odds not quite to surrounding water substance, so the alimentation which surrounding water substance temperature toward micro-modular could be neglected. It is meaning that the temperature alimentation about surrounding water substance toward micro-modular could not be considered. So the sum of the number of variations for caloricity of passes in and out micro-modular and the procreant caloricity of convection equal the caloricity of total variation in micro-modular. The transportation equation of water temperature in groundwater is expressed as:

$$
\frac{\partial T}{\partial t}-C_{L} v \nabla T-\nabla\left(K_{e q} \nabla T\right)=0
$$

Where $\mathrm{C}_{\mathrm{L}}$ is the specific heat of water $\left(\mathrm{J} \cdot \mathrm{kg}^{-1} \cdot \mathrm{K}^{-1}\right)$; $\mathrm{K}_{\mathrm{eq}}$ is the equivalent heat conductivity $\left(\mathrm{W} \cdot \mathrm{m}^{-1} \cdot \mathrm{K}^{-1}\right)$; $\mathrm{T}$ is the temperature (K).

\subsection{Darcy's Law for Consider Temperature}

The conventional Darcy's law difficult of meet the challenge into consideration when consider temperature conditions for pollution transportation in groundwater, because the temperature can effect the soil permeability coefficient and the velocity water flow in groundwater. So the conventional Darcy's law should be improved and satisfaction the model demand. For Darcy's law for consider temperature, this article direct reference the deduce result about Peng Zezhou scholar ${ }^{[5]}$ :

$$
v=-K\left(\nabla h+A \rho_{\mathrm{w}} T g\right)
$$

Where $\mathrm{A}$ is the diffusion coefficient of hot capacity $\left(\mathrm{m}^{2}\right) ; \mathrm{g}$ is the acceleration of gravity $\left(\mathrm{m} \cdot \mathrm{s}^{-2}\right)$.

\subsection{The Transportation Model for Consider Temperature}

The fundamental equation of pollution transportation for considers temperature in groundwater has transportation equation of water temperature, water flow continuity equation, Darcy's law for consider temperature and pollution transportation equation. For considers temperature, the four equations coupled the transportation model of pollution in groundwater is expressed as:

$$
\left\{\begin{array}{l}
I=\left(\theta_{s}-\theta_{0}\right) \mathrm{Z}_{f} \\
q=K_{t}\left(1+\frac{H_{m}}{Z_{f}(t)}\right) \\
\frac{\partial T}{\partial t}-C_{L} v \nabla T-\nabla\left(K_{e q} \nabla T\right)=0 \\
\frac{\partial\left(\rho_{w} h\right)}{\partial t}=\nabla\left(\rho_{w} \mathrm{~K} \nabla \mathrm{h}\right) \\
v=-K\left(\nabla h+A \rho_{\mathrm{w}} T g\right) \\
\eta_{e} \frac{\partial C}{\partial t}-\nabla\left(\eta_{e} D \nabla C\right)-\nabla(C v)=0
\end{array}\right.
$$

Where $\mathrm{C}$ is the transportation concentration of pollution $\left(\mathrm{mg} \cdot \mathrm{L}^{-1}\right) ; \mathrm{D}$ is the dispersion coefficient $\left(\mathrm{m}^{2} \cdot \mathrm{s}^{-1}\right) ; \mathrm{h}$ is the pressure head $(\mathrm{m}) ; \mathrm{K}$ is the permeability coefficient $\left(\mathrm{m} \cdot \mathrm{s}^{-1}\right) ; \mathrm{t}$ is the time $(\mathrm{d}) ; \mathrm{v}$ is the current velocity $\left(\mathrm{m} \cdot \mathrm{s}^{-1}\right) ; \rho_{\mathrm{w}}$ is the water density $\left(\mathrm{kg} \cdot \mathrm{m}^{-3}\right) ; \eta_{\mathrm{e}}$ is the porosity $(\%)$.

\section{Presumption the Transportation Model}

In order to simplified the transportation model, this article 
made presumption as follows:

(1) Incompressible soil and water;

(2) Uniformity earthiness;

(3) Constant the density of water and specific heat capacity;

(4) The effect of temperature on the soil water potential can be attributed to the surface tension of the temperature;

(5) In a certain moisture condition, temperature can affect the permeability coefficient of the single attributed to the influence of temperature on hydrodynamic viscous coefficient.

According to presumption, the transportation model for consider temperature could be simplified:

$$
\left\{\begin{array}{l}
I=\left(\theta_{s}-\theta_{0}\right) \mathrm{Z}_{f} \\
q=K_{t}\left(1+\frac{H_{m}}{Z_{f}(t)}\right) \\
\frac{\partial T}{\partial t}-C_{L} v \nabla T-K_{e q} \nabla^{2} T=0 \\
\frac{\partial h}{\partial t}=\mathrm{K} \nabla^{2} h \\
v=-\frac{K}{\eta_{e}}\left(\nabla h+\frac{K_{e q} T g}{C_{L}}\right) \\
\frac{h_{r}(\theta)}{\sigma_{T}}=h^{*}(\theta) \\
K_{T}(\theta) \eta(T)=K^{*}(\theta) \\
\eta_{e} \frac{\partial C}{\partial t}-\nabla\left(\eta_{e} D \nabla C\right)-\nabla(C v)=0
\end{array}\right.
$$

Eq (5) is the transportation model for consider temperature. The model could be solved incorporation initial and boundary conditions.

\section{Solution the Transportation Model}

The model initial condition includes initial value of pollution concentration and pressure head and water temperature. When $\mathrm{t}=0$, the initial condition is expressed as:

$$
\begin{gathered}
\mathrm{C}(\mathrm{x}, \mathrm{z}, 0)=\mathrm{C}_{0}(\mathrm{x}, \mathrm{z}) \\
\mathrm{h}(\mathrm{x}, \mathrm{z}, 0)=\mathrm{h}_{0}(\mathrm{x}, \mathrm{z}) \\
\mathrm{T}(\mathrm{x}, \mathrm{z}, 0)=\mathrm{T}_{0}(\mathrm{x}, \mathrm{z})
\end{gathered}
$$

Where $\mathrm{C}_{0}(\mathrm{x}, \mathrm{z})$ is the initial value of pollution concentration; $\mathrm{h}_{0}(\mathrm{x}, \mathrm{z})$ is the initial value of pressure head; $\mathrm{T}_{0}(\mathrm{x}, \mathrm{z})$ is the initial value of water temperature.

The model boundary condition includes boundary value of pollution concentration and pressure head. When infinite distance, the boundary condition is expressed as:

$$
\begin{aligned}
& C( \pm \infty, \pm \infty, t)=0 \\
& h( \pm \infty, \pm \infty, t)=0
\end{aligned}
$$

The temperature boundary use Neumann condition, it is meaning that the solving process must thermal insulation, and then the temperature boundary condition is expressed as:

$$
\vec{n} \cdot\left(K_{e q} \nabla T\right)=0
$$

The transportation model could be solved after determined initial and boundary conditions.

\section{Application the Transportation Model}

The established transportation model of pollution in groundwater reflected the pollutions' situation with time and spaces' change of the concentration on transportation process in groundwater, which is the transference regularity of pollution in groundwater. This article solved the transportation model of pollution in groundwater utilize the software of Femlab, simulated the distribution pattern of pollution concentration in 20 years. In numerical implementation, $\mathrm{C}_{0}=1.12 \mathrm{mg} \cdot \mathrm{L}^{-1}, \quad \mathrm{~h}_{0}=0.1 \mathrm{~m}, \quad \alpha_{\mathrm{L}}=2 \mathrm{~m}, \quad \alpha_{\mathrm{T}}=0.4 \mathrm{~m}$, $\mathrm{K}=6.65 \times 10^{-9} \mathrm{~m} \cdot \mathrm{s}^{-1}, \eta_{\mathrm{e}}=0.43, \mathrm{C}_{\mathrm{L}}=4200, \mathrm{~J} \cdot \mathrm{kg}^{-1} \cdot \mathrm{K}^{-1}, \mathrm{~K}_{\mathrm{eq}}=0.613$. The initial temperature in groundwater $\mathrm{T}_{0}=290 \mathrm{~K}$, the initial temperature in pollution source $\mathrm{T}_{01}=303 \mathrm{~K}$, the initial head $\mathrm{h}_{0}=0.1 \mathrm{~m}$. Through repeated simulation, the simulation context determined $5 \mathrm{~km} \times 50 \mathrm{~m}$ and the co-ordinate of the pollution source is $(1.5 \mathrm{~km}, 0)$.

Keep the same depth and the same time, in space ground $10 \mathrm{~m}$ depth determined 3 observing point parting $\mathrm{x}=1.5 \mathrm{~km}$, $2.5 \mathrm{~km}$ and $3.5 \mathrm{~km}$ and serial number parting $1 \#, 2 \#, 3 \#$ shows Fig 1. Also, keep the same plane and the same time, in $\mathrm{x}=1.5 \mathrm{~km}$ determined 3 observing point parting $\mathrm{z}=15 \mathrm{~m}, 25 \mathrm{~m}$ and $35 \mathrm{~m}$ and serial number parting 4\#, 5\#, 6\# shows Fig 2 .

Figure 1 is the same depth and the same time, the change trend between concentration and temperature in different position of the point. Fig 1 shows that:

(1) The more close to the pollution source, the concentration is larger, the farther away from the source of pollution; the concentration value is small, which is consistent with the trend of pollution in the general case.

(2) With the increase of temperature, the concentration of pollution increased, among them, the higher the temperature, the rising trend is more obvious, that the migration and diffusion of pollution in the role of temperature.

Figure 2 is the same position and the same time, the change trend between concentration and temperature in different depth point. Fig 2 shows that:

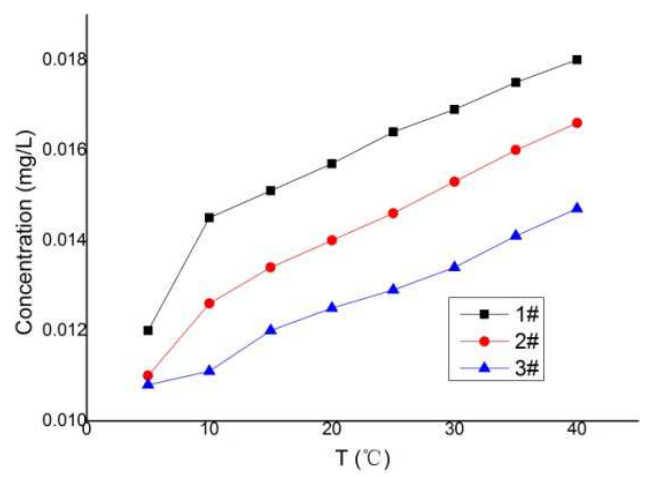

Fig. 1. The change trend between concentration and temperature in different position of the point. 


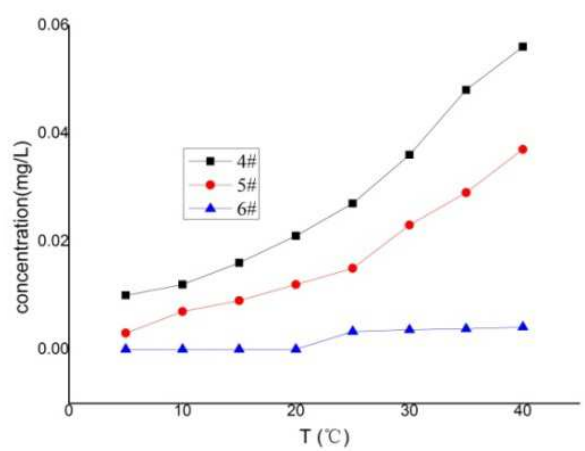

Fig. 2. The change trend between concentration and temperature in different depth point.

(1) The more close to the pollution source (The depth is smaller), the concentration is larger, the farther away from the source of pollution; the concentration value is small, which is consistent with the trend of pollution in the general case.

(2) With the increase of temperature, the concentration of pollution increased, among them, the higher the temperature, the rising trend is more obvious, that the migration and diffusion of pollution in the role of temperature.

(3) When the temperature is less than $20^{\circ} \mathrm{C}$, the $6 \#$ are unpolluted, pollutant is not within the scope of pollution to the depth, and when the temperature is higher than $20^{\circ} \mathrm{C}$, the $6 \#$ appears the pollution $(\mathrm{C}<0.0033 \mathrm{mg} / \mathrm{L})$, indicating that the temperature not only migration and diffusion of pollutants play a role, but also improve the pollution depth.

(4) The temperature could increase depth of pollution diffusion form point $6 \#$.

\section{Conclusion}

(1) This article considers the temperature influence of pollution transportation base on the transportation model of pollution in groundwater;

(2) The transportation equation of water temperature in groundwater could be established according to the soil water movement model under the influence of temperature, heat balance and transportation diffuse field of micro-modular, reference the Darcy's law for consider temperature and established the transportation model for consider temperature.

(3) The transportation model is solved by soft of Femlab. The result shows that the more close to the pollution source, the concentration is larger, the farther away from the source of pollution; the concentration value is small, which is consistent with the trend of pollution in the general case. With the increase of temperature, the concentration of pollution increased, among them, the higher the temperature, the rising trend is more obvious, that the migration and diffusion of pollution in the role of temperature. The temperature could increase depth of pollution diffusion.

\section{Acknowledgements}

This research was financially supported by the National Science Foundation (51168022) and the scientific research key fund project of Education Department of Yunnan Province (2013Z114).

\section{References}

[1] Li Jingchang, Wei Zhongding. Quality and proposition of groundwater [M]. Beijing: China Building Industry Press, 1983: 148 173(in Chinese)

[2] Shen Jingwen. The proposition of fertilizer pesticide and wastewater irrigation in groundwater. Agricultural Environment Protection, 2009, 11(3): 137 139

[3] Wang Yunquan, Ren Deyi. The differential element leaching experimental investigation of the coal and combustion product [J]. Environmental Science, 1996, 17(1):16 17

[4] Komnitsas, K. Bartzas, G.; Paspaliaris, I: Efficiency of limestone and red mud barriers: Laboratory column studies[J]. Minerals Engineering, 2004, 2:183 194

[5] Peng Zezhou, Ynag Tianhang. Aquatic environment mathematical model and application[M]. Beijing: chemical engineering industry press, 2007, 1(1):5 94

[6] Liu Peng, Huang Ying, The test study of iron ion migration characteristics on pollution laterite, Earth Sciences, 2014, 3(6): $132-136$

[7] Liu Peng, Huang Ying, The Simulation to Water Transport in Unsaturated Soils, Physical and Numerical Simulation Of Geotechnical Engineering, 2012, 12(9) : 79-83

[8] Liu Peng, Huang Ying, Gao Wenxin, The Study of Transportation Regularity for Pollution Laterite, WREP 2014, 2014.6.7-2014.6.9

[9] Liu Peng, Jin Juanjuan, The Study of Transportation Regularity for Different Element, ISWREP2011, 2011.5.20-2011.5.22

[10] Liu Peng, He Min, Jin Juanjuan, The Study of Transportation Regularity Consider Temperature, 2010.10.10-2010.10.11

[11] Shabnam Gholamifarda, Robert Eymardb, Christian Duquennoia. Modeling anaerobic bioreactor landfills in methanogenic phase: Long term and short term behaviors [J]. Water Research, 2008, 42: 5061-5071

[12] Markus Bauer, Beate Fulda, Christian Blodau. Groundwater derived arsenic in high carbonate wetland soils: Sources, sinks, and mobility [J]. Science of the Total Environment, 2008, 401: $109-120$

[13] Abdelmalek Bouazzaa, Stephan Jefferis, Thaveesak Vangpaisal Investigation of the effects and degree of calcium exchange on the Atterberg limits and swelling of geosynthetic clay liners when subjected to wet-dry cycles [J]. Geotextiles and Geomembranes, 2007, 25: 170-185

[14] Lu Q, He Z L L, Graetz D A, Stoffella R J, Yang X E. Phytoremediation to remove nutrients and improve entropic storm waters using water lettuce [J]. Envimnmenial Science and Pollution Research, 2010, 17: 84-96

[15] Kirzhner F, Zimmels Y, Malkovskaja A, Starosvetsky J. Removal of microbial biofilm on Water Hyacinth plants roots by ultrasonic treatment [J]. Ultrasonics, 2009, 49: 153-158 